\title{
A case-control study of lung cancer with special reference to the effect of air pollution in Poland
}

\author{
Wieslaw Jedrychowski, Heiko Becher, Jürgen Wahrendorf, Zenona Basa-Cierpialek
}

\begin{abstract}
Study objective-The aim of the study was to assess the affect of inhaled pollutants on lung cancer risk.

Design-The study was a retrospective case-control survey of lung cancer deaths over a six year period (1980-1985). Information on occupation, smoking habits, and residency was collected from next of kin. Classification of exposure to community air pollution was based on measured levels of total suspended particular matter and sulphur dioxide.

Setting-Cases and controls had been resident in the city of Cracow, Poland.

Participants-Cases were male (n $=901$, questionnaire response rate $70.7 \%$ ) and female $(n=198$, response rate $65 \cdot 1 \%)$ lung cancer deaths; controls were deaths from other causes, excluding other respiratory diseases, and frequency matched by age and sex (males $n=875$, response rate $73.5 \%$; females $n=198$, response rate $64 \cdot 0 \%$ ).

Main results-Lung cancer risk was found to depend strongly on total cigarette consumption, on age at starting to smoke, and on time since stopping smoking. Relative risk estimates for occupational exposure in iron and steel foundries or in other industries were significantly increased in males. Relative risk in men for highest air pollution level was 1.48 (95\% confidence interval $1 \cdot 08-2 \cdot 01$ ), while in women the increase was not significant. The joint action of the risk facts of smoking, occupational exposure, and air pollution was found to fit almost perfectly into a multiplicative model.
\end{abstract}

Conclusions-Under conditions found in Cracow, air pollution may increase lung cancer risk, acting multiplicatively with known risk factors such as smoking and industrial exposure.

The aetiology of bronchogenic carcinoma involves the interplay of multiple environmental and host factors, and the relative contribution of each is not completely clear. One essential environmental factor is the presence of respiratory tract carcinogens in inhaled air, derived from sources such as cigarette smoke, combustion of coal and oil, and industrial effluents. It is beyond any doubt that the main and best proved cause of lung cancer is tobacco smoking ${ }^{1}$ but a careful assessment of other potential factors such as air pollution or occupation remains warranted. The rising lung cancer rate among non-smokers indicates that factors in addition to personal smoking habits have a significant effect on the mortality rate from this disease. ${ }^{2}$ The hypothesis that air pollution might be a factor responsible for developing lung cancer is based on two observations. The first is that urban pollution contains carcinogenic substances and is mutagenic $;^{3-6}$ the second stems from the difficulty expressed by several authors in explaining the excess mortality from lung cancer among inhabitants of towns in comparison with rural areas only by different smoking habits or increased occupational exposure. ${ }^{7-11}$ It is, however, also argued that relatively small differences in smoking habits between rural and urban areas, eg, a few years later in starting to smoke, might explain these differences. ${ }^{12}$ An interesting contribution to the hypothesis that air pollution may be a relevant factor in the genesis of the lung cancer was also provided by international migrant studies which showed a persisting excess lung cancer mortality rate for immigrants from countries with higher air pollution. ${ }^{13} 14$

Preliminary analyses showed that Cracow, when compared with Poland overall, had an excess of lung cancer deaths in men as well as in women, and this had been discussed in relation to the very high air pollution in the Cracow area. ${ }^{15}$ However, several factors other than air pollution could account for the observed excess in mortality rates. These could include better reporting of deaths due to lung cancer in Cracow, higher prevalence of smoking habits, or more occupational hazards.

An overview of epidemiological studies on air pollution and lung cancer is given in table I. Most are descriptive studies and there is only one case-control study of limited size. A case-control study was therefore conducted in Cracow in order to assess the effect of air pollution on lung cancer risk in combination with smoking and occupation. A detailed analysis of lung cancer risk associated with occupational exposure, in particular foundry employment, had already been performed in the male subpopulation of this study. ${ }^{27}$ This paper presents a thorough multivariate analysis of all the data.

\section{Methods}

STUDY AREA AND AIR POLLUTION MEASUREMENTS

Cracow covers approximately $230 \mathrm{~km}^{2}$ with a population of about 700000 inhabitants. The town is situated in the inversion valley of the Vistula River where long inversion phenomena occur as well as a great number of foggy and misty days. The urban area, and especially the centre of 
Table I Summary of studies on air pollution and lung cancer

\begin{tabular}{lll}
\hline Study type & Results & Reference No \\
\hline Descriptive study & $\begin{array}{l}\text { Urban-rural differences in lung cancer } \\
\text { rates (total population) } \\
\text { Same, for non-smokers only }\end{array}$ & $16-18$ \\
Case-control study & $\begin{array}{l}\text { Same, adjusted for smoking } \\
\text { No effect for air pollution; possibility } \\
\text { of synergistic effect between smoking } \\
\text { and air pollution discussed }\end{array}$ & $20-25$ \\
\hline
\end{tabular}

the city, is characterised by little wind and frequent periods of stillness. The quickly growing metallurgical industry and the large proportion of individual oven based heating devices in the old town, with little central heating until recent times, are considered the main sources of air pollution in Cracow. In central Cracow average annual mean concentration of total suspended particulate matter of $150 \mu \mathrm{g} / \mathrm{m}^{3}$ and sulphur dioxide $\left(\mathrm{SO}_{2}\right)$ above $100 \mu \mathrm{g} / \mathrm{m}^{3}$ is high for Europe, and close to maximum short term tolerance levels of western countries. ${ }^{28}$ Higher concentrations in the autumn and winter reflect the greater emissions of smoke and ash from coal fired furnaces for room heating. Green areas, parks and gardens cover only about $5 \%$ of the total area of the city.

A classification of exposure to community air pollution was based on measured levels of total suspended particles and sulphur dioxide. The ambient air characteristics for the study area were determined by a network of 20 sampling stations designed to measure total suspended particulate matter and $\mathrm{SO}_{2}$ every day. Sampling was continued over eight years from 1973 to the end of 1980. Isopleths for pollutant levels were constructed for the Cracow study area using graphics package computer programs from the National Center for Atmospheric Research, Boulder, Colorado. ${ }^{29}$ These isopleths categorised the total suspended particulate matter values into three levels: (a) less than $120 \mu \mathrm{g} / \mathrm{m}^{3}$, (b) $120-150$ $\mu \mathrm{g} / \mathrm{m}^{3}$, and (c) higher than $150 \mu \mathrm{g} / \mathrm{m}^{3}$. Sulphur dioxide data were categorised into four levels: (a) less than $56 \mu \mathrm{g} / \mathrm{m}^{3}$, (b) $56-96 \mu \mathrm{g} / \mathrm{m}^{3}$, (c) $96-104$ $\mu \mathrm{g} / \mathrm{m}^{3}$, and (d) higher than $104 \mu \mathrm{g} / \mathrm{m}^{3}$. The last place of residence of an individual was then located on the isopleth maps to classify the suspended matter and $\mathrm{SO}_{2}$ level. A combined index of air pollution based on total suspended matter (TSP) and $\mathrm{SO}_{2}$ concentrations was developed subsequently using three levels: low = $\mathrm{TSP}<150 \mu \mathrm{g} / \mathrm{m}^{3}$ and $\mathrm{SO}_{2}<104 \mu \mathrm{g} / \mathrm{m}^{3} ;$ medium $=\mathrm{TSP}>150 \mu \mathrm{g} / \mathrm{m}^{3}$ or $\mathrm{SO}_{2}>104 \mu \mathrm{g} / \mathrm{m}^{3}$ but not both; high $=\mathrm{TSP}>150 \mu \mathrm{g} / \mathrm{m}^{3}$ and $\mathrm{SO}_{2}>104$ $\mu \mathrm{g} / \mathrm{m}^{3}$.

\section{STUDY POPULATION}

Male and female residents of Cracow whose deaths were attributed to lung cancer on the death certificate and whose death occurred between 1 January 1980 and 31 December 1985 were selected as cases. Altogether 1579 subjects met these criteria. The control subjects were selected from the Cracow death register as the first entry of the same sex and \pm 5 years of age following each case. Diseases of the respiratory tract (International Classification of Diseases, ninth revision [ICD-9] 140-150, 160-165, 480-519), were excluded. Through this procedure 1491 controls were selected, with a distribution for age and date of death comparable to the cases (frequency matched design).

Through self administered mailed questionnaire, data were collected concerning demographic variables, residency, occupation and smoking habits. The questionnaires were answered by the next of kin of cases and controls. Socioeconomic status was assessed by education level, ie, the highest grade of the formal education completed. Occupational exposure was assessed by job title and a substance list. Details are given in Becher et al. ${ }^{27}$ In the female series very little exposure to one of the substances was reported. Therefore, in order to control sufficiently for confounding, a variable "manual worker" was formed which is equivalent to blue collar work. Data concerning smoking habits included the year of starting smoking, an average number of cigarettes smoked daily, and duration of smoking. From the smoking history, three variables were formed to describe the effect of smoking on lung cancer risk: average consumption, age at starting to smoke, time elapsed since stopping smoking.

Most of the respondents were spouses for male cases and controls, and offsprings for female cases and controls. Two reminders were sent before a subject was considered as a non-respondent. On average the response rate for cases was $70.7^{\circ}$ in males and $65.1 \%$ in females, and the corresponding numbers for controls were $73.5^{\circ} \mathrm{o}$ and $64.0 \%$, resulting in 901 (198) male (female) cases and 875 (198) male (female) controls. The response rates were roughly similar across the age groups in both cases and controls (table I). There was a slightly lower response rate for female cases and controls in the highly polluted area of the city.

For statistical analysis logistic regression models $^{30}$ were fitted to the data using the statistical software packages SAS and GLIM for unconditional maximum likelihood estimation of the regression parameters. This analysis is appropriate for a frequency matched design. The final models (for males and females separately) were obtained by subsequently adding variables into the model which gave a significant improvement of the fit. All variables except age were entered as categorical variables into the model. The factor "age" was necessary because the selection procedure of the controls and a higher response rate in higher age groups for controls required an age adjustment. All confidence intervals (CI) given are on the $95^{\circ}{ }_{0}$ level. Relative risks are estimated from the antilog of the regression coefficient estimates in the logistic regression model. The proportion of lung cancer cases which are attributable to one or all risk factors (attributable risk, AR) were estimated by adopting the method of Bruzzi et al. ${ }^{31}$

\section{Results}

Due to the selection procedure and the differences in age specific response rates between cases and controls (tables II, III), controls were on average slightly older than the cases. The mean age of cases was 63.3 (SD 12.6) years in males and 65.3 $(11 \cdot 1)$ in females. The corresponding values for controls were $66.8(12 \cdot 6)$ years in males and $76 \cdot 1$ $(10 \cdot 3)$ years in females. 
Table II Response rates (\%) for cases and controls by age and air pollution area

\begin{tabular}{|c|c|c|c|c|}
\hline & \multicolumn{2}{|l|}{ Males } & \multicolumn{2}{|l|}{ Females } \\
\hline & $\begin{array}{l}\text { Case } \\
(\mathrm{n}=901)\end{array}$ & $\begin{array}{l}\text { Control } \\
(\mathbf{n}=875)\end{array}$ & $\begin{array}{l}\text { Case } \\
(\mathrm{n}=198)\end{array}$ & $\begin{array}{l}\text { Control } \\
(n=198)\end{array}$ \\
\hline $\begin{array}{c}\text { Age (years) } \\
-49 \\
50-59 \\
60-69 \\
70-79 \\
80-\end{array}$ & $\begin{array}{l}71 \cdot 0 \\
72 \cdot 0 \\
73 \cdot 0 \\
67 \cdot 0 \\
71 \cdot 0\end{array}$ & $\begin{array}{l}68 \cdot 0 \\
67 \cdot 0 \\
76 \cdot 0 \\
76 \cdot 0 \\
77 \cdot 0\end{array}$ & $\begin{array}{l}68 \cdot 0 \\
62 \cdot 0 \\
67 \cdot 0 \\
64 \cdot 0 \\
64 \cdot 0\end{array}$ & $\begin{array}{l}50 \cdot 0 \\
58 \cdot 0 \\
60 \cdot 0 \\
68 \cdot 0 \\
69 \cdot 0\end{array}$ \\
\hline $\begin{array}{l}\text { Air pollutio } \\
\text { low } \\
\text { medium } \\
\text { high }\end{array}$ & $\begin{array}{l}72 \cdot 4 \\
64 \cdot 2 \\
70 \cdot 1\end{array}$ & $\begin{array}{l}74.5 \\
73.7 \\
68.9\end{array}$ & $\begin{array}{l}67 \cdot 4 \\
58 \cdot 7 \\
66 \cdot 7\end{array}$ & $\begin{array}{l}70 \cdot 2 \\
53 \cdot 8 \\
61 \cdot 4\end{array}$ \\
\hline
\end{tabular}

Table III Age distribution by sex for cases and controls

\begin{tabular}{|c|c|c|c|c|c|c|c|c|}
\hline \multirow{3}{*}{ Age (years) } & \multicolumn{4}{|c|}{ Males } & \multicolumn{4}{|c|}{ Females } \\
\hline & \multicolumn{2}{|c|}{ Case } & \multicolumn{2}{|c|}{ Control } & \multicolumn{2}{|c|}{ Case } & \multicolumn{2}{|c|}{ Control } \\
\hline & $\mathbf{n}$ & $\%$ & $\mathbf{n}$ & $\%$ & $\mathbf{n}$ & $\%$ & n & $\%$ \\
\hline $\begin{array}{r}-49 \\
50-59 \\
60-69 \\
70-79 \\
80-\end{array}$ & $\begin{array}{r}82 \\
254 \\
288 \\
235 \\
42\end{array}$ & $\begin{array}{r}9 \cdot 1 \\
28 \cdot 2 \\
31 \cdot 9 \\
26 \cdot 1 \\
4 \cdot 7\end{array}$ & $\begin{array}{r}80 \\
164 \\
222 \\
283 \\
126\end{array}$ & $\begin{array}{r}9.2 \\
18.7 \\
25.4 \\
32.3 \\
14.4\end{array}$ & $\begin{array}{l}13 \\
51 \\
58 \\
58 \\
18\end{array}$ & $\begin{array}{r}6.6 \\
25.7 \\
29.3 \\
29.3 \\
9.1\end{array}$ & $\begin{array}{r}3 \\
14 \\
25 \\
77 \\
79\end{array}$ & $\begin{array}{r}1.5 \\
7 \cdot 1 \\
12.6 \\
38.9 \\
39.9\end{array}$ \\
\hline
\end{tabular}

Table IV shows the distribution of total suspended particulate matter (TSP), $\mathrm{SO}_{2}$, and the resulting variable "air pollution". The two variables TSP and $\mathrm{SO}_{2}$ were strongly correlated. For males the crude odds ratios do not show an effect of air pollution on lung cancer risk (OR = 0.9 for level 2 and 1.14 for level 3 ). For females the crude odds ratio for the medium level was $2 \cdot 26$ and declined to 0.75 for the highest level. Combining these two levels results in an odds ratio of $1 \cdot 25$.
Table $\mathrm{V}$ outlines the results of the model search procedure in the multivariate analysis. The distribution of the other risk factors among cases and controls is given in tables VI and VII. Starting with the baseline model, variables were added into the model in the order of the expected magnitude of their relative risk. Relative risk estimates given in tables VI and VII are based on the final model No 4. Regression coefficients remained stable during the model search procedure, and changing the order of entering the variables resulted in the same final model.

All smoking variables showed a significant effect on lung cancer risk. However, in the females numbers were insufficient to allow such a detailed analysis as in males. For some of the cases and controls the amount of smoking was not given and therefore the additional variable "dose missing" had been introduced into the subsequent logistic models. The variable "dose" had the strongest effect on lung cancer risk in males and females, with relative risk estimates up to $7.68\left(95^{\circ}{ }_{0} \mathrm{CI}\right.$ 5.15-11.47) (males) and $7 \cdot 37\left(95^{\circ} \circ\right.$ CI $2 \cdot 20$ 24.69) (females). For males "start smoking before age 17 " gives an estimated factor of $1.66\left(95^{\circ}{ }^{\circ} \mathrm{CI}\right.$ 1.19-2.33). Stopping smoking significantly reduced lung cancer risk by a factor of $0.40\left(95^{\circ}\right.$ 。 CI 0.29-0.56) (time since stopped smoking $>10$ years). For females early age at starting to smoke increased the lung cancer risk by an estimated factor of $1.77(95 \%$ CI 0.68-4.60; while stopping smoking reduced the risk by a factor of $0.54\left(95^{\circ}\right.$ o CI 0.17-1.50). Different age groups were analysed separately (results not shown). The parameter estimates remained virtually the same.

The lung cancer risk due to occupational exposure has been dealt with in detail before. ${ }^{27}$
Table IV Distribution of total suspended particulate matter (TSP), $\mathrm{SO}_{2}$ and air pollution for cases and controls, males and females

\begin{tabular}{|c|c|c|c|c|c|c|c|c|}
\hline & \multicolumn{8}{|c|}{$\operatorname{TSP}\left(\mu \mathrm{g} / \mathrm{m}^{3}\right)$} \\
\hline & \multicolumn{4}{|l|}{ Cases } & \multicolumn{4}{|c|}{ Controls } \\
\hline & $<120$ & $120-150$ & $>150$ & total & $<120$ & $120-150$ & $>150$ & total \\
\hline $\begin{array}{c}\mathrm{SO}_{2}\left(\mu \mathrm{g} / \mathrm{m}^{3}\right) \\
<56 \\
56-96 \\
96-104 \\
>104\end{array}$ & $\begin{array}{r}154 \\
416 \\
34 \\
20\end{array}$ & $\begin{array}{r}3 \\
19 \\
24 \\
49\end{array}$ & $\begin{array}{r}0 \\
31 \\
29 \\
122\end{array}$ & $\begin{array}{r}157 \\
466 \\
87 \\
191\end{array}$ & $\begin{array}{r}128 \\
409 \\
48 \\
34\end{array}$ & $\begin{array}{r}2 \\
19 \\
25 \\
43\end{array}$ & $\begin{array}{r}0 \\
36 \\
27 \\
104\end{array}$ & $\begin{array}{l}130 \\
464 \\
100 \\
181\end{array}$ \\
\hline Total & 524 & 95 & 182 & 901 & 619 & 89 & 167 & 875 \\
\hline Air pollution & $\begin{array}{l}\text { low } \\
650\end{array}$ & $\begin{array}{l}\text { medium } \\
129\end{array}$ & $\begin{array}{l}\text { high } \\
122\end{array}$ & & $\begin{array}{l}\text { low } \\
631\end{array}$ & $\begin{array}{l}\text { medium } \\
140\end{array}$ & $\begin{array}{r}\text { high } \\
104\end{array}$ & \\
\hline $\operatorname{sOn}\left(\mu \mathrm{g} / \mathrm{m}^{3}\right)$ & & & & Females & & & & \\
\hline $\begin{array}{l}<56 \\
56-96 \\
96-104 \\
>104\end{array}$ & $\begin{array}{l}16 \\
81 \\
13 \\
10\end{array}$ & $\begin{array}{r}0 \\
5 \\
9 \\
14\end{array}$ & $\begin{array}{r}0 \\
7 \\
13 \\
30\end{array}$ & $\begin{array}{l}16 \\
93 \\
35 \\
54\end{array}$ & $\begin{array}{r}26 \\
91 \\
7 \\
6\end{array}$ & $\begin{array}{l}0 \\
3 \\
7 \\
6\end{array}$ & $\begin{array}{r}0 \\
3 \\
6 \\
43\end{array}$ & $\begin{array}{l}26 \\
97 \\
20 \\
55\end{array}$ \\
\hline Total & 120 & 28 & 50 & 198 & 130 & 16 & 52 & 198 \\
\hline Air pollution: & $\begin{array}{l}\text { low } \\
124\end{array}$ & $\underset{44}{\text { medium }}$ & $\begin{array}{c}\text { high } \\
30\end{array}$ & & $\begin{array}{l}\text { low } \\
134\end{array}$ & $\underset{21}{\operatorname{medium}}$ & $\begin{array}{r}\text { high } \\
43\end{array}$ & \\
\hline
\end{tabular}

Table $V$ Results of model selestion procedure for the final logistic models.

\begin{tabular}{|c|c|c|c|c|c|c|c|c|c|}
\hline \multirow[b]{2}{*}{ No } & \multirow[b]{2}{*}{$\begin{array}{l}\text { Variable added to } \\
\text { previous model }\end{array}$} & \multicolumn{4}{|l|}{ Males } & \multicolumn{4}{|l|}{ Females } \\
\hline & & Deviance & $\begin{array}{l}\text { Change in } \\
\text { deviance }\end{array}$ & $\begin{array}{l}\text { Change } \\
\text { in df }\end{array}$ & $\mathrm{p}^{\star}$ & Deviance & $\begin{array}{l}\text { Change in } \\
\text { deviance }\end{array}$ & $\begin{array}{l}\text { Change } \\
\text { in df }\end{array}$ & $\mathrm{p}^{\star}$ \\
\hline $\begin{array}{l}0 \\
1 \\
2 \\
3\end{array}$ & $\begin{array}{l}\text { (Baseline model) } \\
\text { Age } \\
\text { Smoking } \\
\text { Occupational exposure }\end{array}$ & $\begin{array}{l}2461 \cdot 7 \\
2419 \cdot 1 \\
2206 \cdot 9\end{array}$ & $\begin{array}{r}42 \cdot 6 \\
212 \cdot 2\end{array}$ & $\begin{array}{l}1 \\
8\end{array}$ & $\begin{array}{l}<0.001 \\
<0.001\end{array}$ & $\begin{array}{l}549 \cdot 0 \\
459 \cdot 6 \\
412 \cdot 9\end{array}$ & $\begin{array}{l}89 \cdot 4 \\
46 \cdot 7\end{array}$ & $\begin{array}{l}1 \\
6\end{array}$ & $\begin{array}{l}<0.001 \\
<0.001\end{array}$ \\
\hline $\begin{array}{l}3 \\
4\end{array}$ & $\begin{array}{l}\text { Occupational exposure } \\
\text { (job category) } \\
\text { Air pollution }\end{array}$ & $\begin{array}{l}2180 \cdot 7 \\
2174 \cdot 3\end{array}$ & $\begin{array}{r}26 \cdot 2 \\
6 \cdot 4\end{array}$ & $\begin{array}{l}2 \\
2\end{array}$ & $\begin{array}{l}<0.001 \\
<0.05\end{array}$ & $\begin{array}{l}409 \cdot 5 \\
409 \cdot 1\end{array}$ & $\begin{array}{l}3 \cdot 4 \\
0.4\end{array}$ & $\begin{array}{l}1 \\
1\end{array}$ & $\begin{array}{l}<0.1 \\
>0.1\end{array}$ \\
\hline
\end{tabular}

* Significance of improving the fit relative to the preceding model 
Table VI Odds ratio estimates (adjusted to age) based on multiple logistic model. Males, Cracow, Poland, 1980 1985

Table VII Odds ratio estimates (adjusted to age) based on multiple logistic model. Females, Cracow, Poland, 19801985

\begin{tabular}{|c|c|c|c|c|}
\hline Variable & $\begin{array}{l}\text { Cases } \\
(\mathrm{n}=901)\end{array}$ & $\begin{array}{l}\text { Controls } \\
(\mathrm{n}=875)\end{array}$ & $\mathbf{R R}$ & $95^{\circ} \circ \mathrm{CI}$ \\
\hline 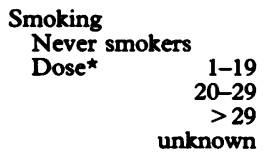 & $\begin{array}{r}49 \\
131 \\
426 \\
278 \\
17\end{array}$ & $\begin{array}{r}219 \\
180 \\
295 \\
143 \\
38\end{array}$ & $\begin{array}{l}1.0 \\
3.48 \\
6 \cdot 16 \\
7 \cdot 69 \\
2 \cdot 41\end{array}$ & $\begin{array}{l}(2.33,5.19) \\
(4 \cdot 25,8.90) \\
(5.15,11 \cdot 47) \\
(1.24,4.68)\end{array}$ \\
\hline $\begin{array}{lr}\text { Age at start } \quad \begin{array}{r}<17 \\
17-18\end{array}\end{array}$ & $\begin{array}{l}135 \\
239\end{array}$ & $\begin{array}{r}66 \\
146\end{array}$ & $\begin{array}{l}1.66 \\
1.30\end{array}$ & 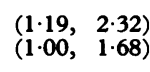 \\
\hline $\begin{array}{cr}\begin{array}{c}\text { Years since } \\
\text { stopped }\end{array} & >10 \\
>5-10\end{array}$ & $\begin{array}{l}73 \\
64\end{array}$ & $\begin{array}{r}138 \\
58\end{array}$ & $\begin{array}{l}0.40 \\
0.66\end{array}$ & 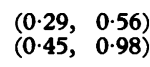 \\
\hline $\begin{array}{l}\text { Occupational exposure } \\
\text { No exposure } \\
\text { In foundries } \\
\text { In other industries }\end{array}$ & $\begin{array}{l}561 \\
106 \\
234\end{array}$ & $\begin{array}{r}677 \\
72 \\
126\end{array}$ & $\begin{array}{l}1.0 \\
1.56 \\
1.96\end{array}$ & $\begin{array}{l}(1 \cdot 10,2.21) \\
(1.51,2.55)\end{array}$ \\
\hline $\begin{array}{l}\text { Air pollution } \\
\text { Low } \\
\text { Medium } \\
\text { High }\end{array}$ & $\begin{array}{l}650 \\
129 \\
122\end{array}$ & $\begin{array}{l}631 \\
140 \\
104\end{array}$ & $\begin{array}{l}1.0 \\
1.00 \\
1.46\end{array}$ & $\begin{array}{l}(0.75,1.33) \\
(1.06,1.99)\end{array}$ \\
\hline
\end{tabular}

$\mathbf{R R}=$ relative risk; $\mathrm{CI}=$ confidence interval

* Dose $=$ average number of cigarettes smoked daily

\begin{tabular}{|c|c|c|c|c|}
\hline Variable & $\begin{array}{l}\text { Cases } \\
(\mathrm{n}=198)\end{array}$ & $\begin{array}{l}\text { Controls } \\
(\mathrm{n}=198)\end{array}$ & $\mathbf{R R}$ & $95^{\circ} \mathrm{O} \mathrm{CI}$ \\
\hline $\begin{array}{l}\text { Smoking } \\
\text { Never smokers } \\
\begin{array}{l}1-19 \\
\text { Dose } \\
20-29 \\
>29 \\
\text { unknown }\end{array}\end{array}$ & $\begin{array}{r}78 \\
37 \\
52 \\
28 \\
3\end{array}$ & $\begin{array}{r}166 \\
10 \\
16 \\
4 \\
2\end{array}$ & $\begin{array}{l}1 \cdot 0 \\
6 \cdot 37 \\
2 \cdot 38 \\
7 \cdot 37 \\
2 \cdot 94\end{array}$ & $\begin{array}{l}(2 \cdot 66,15 \cdot 24) \\
(1 \cdot 17,6 \cdot 86) \\
(2 \cdot 20,24 \cdot 69) \\
(0 \cdot 47,18 \cdot 59)\end{array}$ \\
\hline Age at start & 63 & 11 & 1.77 & $(0.68,4.60)$ \\
\hline $\begin{array}{l}\text { Years since } \\
\text { stopped }\end{array}$ & 13 & 8 & 0.51 & $(0.17,1.50)$ \\
\hline $\begin{array}{l}\text { Occupational exposure } \\
\text { Non-manual worker } \\
\text { Manual worker }\end{array}$ & $\begin{array}{r}166 \\
32\end{array}$ & $\begin{array}{r}183 \\
15\end{array}$ & $\begin{array}{l}1 \cdot 0 \\
2 \cdot 02\end{array}$ & $(0.94,4.35)$ \\
\hline $\begin{array}{l}\text { Air pollution } \\
\text { Low } \\
\text { Medium + high }\end{array}$ & $\begin{array}{r}124 \\
74\end{array}$ & $\begin{array}{r}134 \\
64\end{array}$ & $\begin{array}{l}1 \cdot 0 \\
1 \cdot 17\end{array}$ & $(0.70,1.96)$ \\
\hline
\end{tabular}

$\mathbf{R R}=$ relative risk; $\mathbf{C I}=$ confidence interval

$\star$ Dose $=$ average number of cigarettes smoked daily

For this paper, occupational exposure in iron and steel foundries and occupational exposure in other industries was considered to control for confounding. Both factors significantly increased lung cancer risk (RR 1.56, 95\% CI 1·10-2.21 and RR 1.95, 95\% CI 1.51-2.55 respectively).

Education level and place of birth (urban $v$ rural) did not show an improvement in fitting the multiple logistic model and these factors were therefore ignored in the further steps of the analysis.

The regression risk estimates for the air pollution levels were significant for men, but only for those who lived in the most polluted area (high total suspended particulate matter and high $\mathrm{SO}_{2}$ ). The relative risk for the highest air pollution level in men was 1.46 (95\% CI 1.06-1.99). This is higher than the crude odds ratio given above. For women no trend was observed for the air pollution levels. Using the three level categorisation, the estimated relative risk for the medium level is 1.85 (95\% CI 0.94-3.64) and for the highest level it is $0.76(95 \%$ CI $0.39-1 \cdot 44)$. In the final logistic model for females both categories are combined. The resulting relative risk estimate if $1.17(95 \%$ CI 0.71-1.96). Further comments on the air pollution results are given in the Discussion.

A bias from the death certificate diagnosis by doctors outside hospital and the type of respondent of the mailed questionnaire might have had some impact on the results of our study dealing with smoking and environmental factors. We therefore controlled for the institution responsible for death certification (hospital $v$ general practitioner) and the source of individual information about cases and controls (spouse $v$ others). Models allowing for both these added variables showed virtually the same estimates for smoking categories, occupational exposure and the effect of air pollution.

It has been suggested in published reports that there is an interactive effect between air pollution and other risk factors for lung cancer. ${ }^{26}$ The interaction term has become the subject of some controversy in recent years, since the choice of the underlying functional form of the relative risk function ${ }^{32} 33$ affects its interpretation. Multiplicative relative risk models were fitted for which a positive interaction term would mean an overmultiplicative effect. In order to demonstrate the multiplicativeness, a model was fitted in which the smoking categories were combined into one category "smoker", while the occupational exposure categories and the air pollution categories were both combined according to the former definitions.

The figure shows very well the multiplicative effect of the risk factors of smoking, occupational exposure, and air pollution. In this figure relative risk estimates resulting from separate estimation 


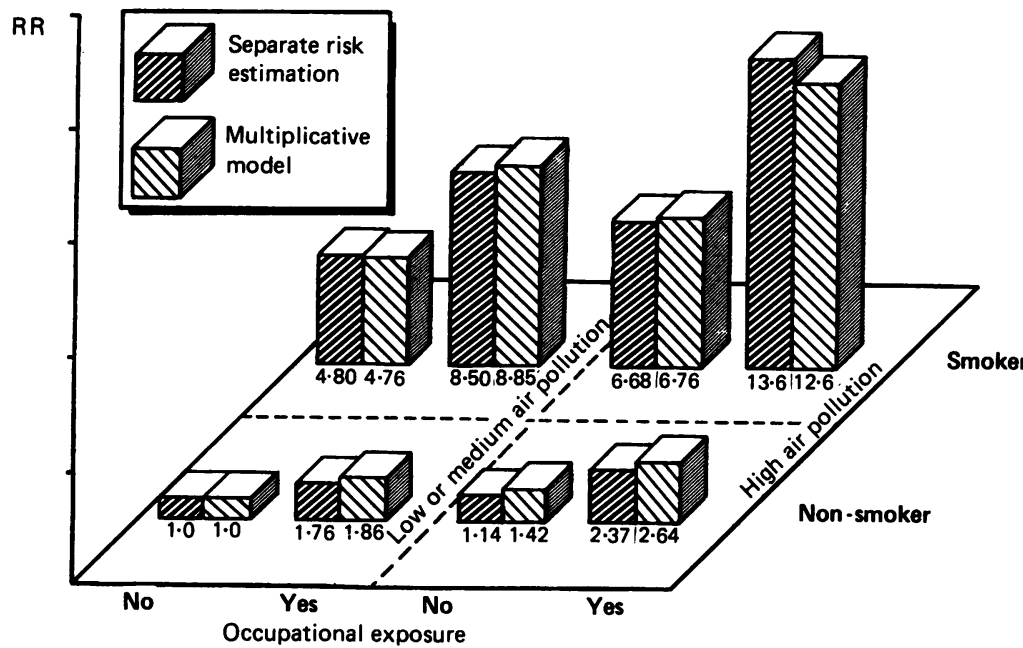

Multiplicative effect of smoking, occupational exposure, and air pollution on risk of lung cancer

Table VIII Estimates of the attributable risk (AR) according to Bruzzi et al. ${ }^{31}$ of each risk factor combination were compared with relative risk estimates under the multiplicative model, and there is almost perfect agreement. The appropriateness of the multiplicative model was further investigated by adding first order interaction terms into the final model. All coefficients were close to zero and non-significant.

Attributable risk estimates are given, based on relative risk estimates from tables VI and VII. Results are given in table VIII, and support the findings of Damber and Larsson ${ }^{34}$ concerning the attributable risk for occupational exposure. The numbers show that preventive actions against

\begin{tabular}{lcc}
\hline & \multicolumn{2}{c}{ AR $\left({ }^{\circ}{ }_{0}\right)$} \\
\cline { 2 - 3 } Variable & Males & Females \\
\hline Smoking & $74 \cdot 7$ & $47 \cdot 6$ \\
Occupational exposure & $20 \cdot 6$ & $8 \cdot 3$ \\
Air pollution & $4 \cdot 3$ & $10 \cdot 5$ \\
All risk factors & $80 \cdot 7$ & $56 \cdot 1$ \\
\hline
\end{tabular}

smoking would have the strongest effect on reducing lung cancer mortality but also a considerable reduction could be achieved by reducing occupational hazards or general air pollution. Differences in sex specific mortality rates, which are about 4-5 times higher for males in Cracow, are therefore largely explained by different prevalence conditions of the risk factors. The attributable risk for all three risk factors was $80.7 \%$ for males and $51 \cdot 1 \%$ for females. Thus the proportion of lung cancer deaths not attributable to the three factors under study is 2.5 times higher in females than in males; however, in terms of absolute rates this is in the same order of magnitude.

Finally, a subgroup was formed from the total sample which included non-smokers only, in order to avoid a residual confounding from smoking. In this analysis an adjustment for age and occupation was performed. Numbers and results are given in table IX. The air pollution categories are the same as in table VII. For both males and females a slightly increased relative risk estimate was found (RR $1 \cdot 45,95 \%$ CI $0 \cdot 74-2 \cdot 87$ and RR $1 \cdot 16,95 \%$ CI $0 \cdot 48-2 \cdot 80$ ) which was not, however, significant.
Discussion

The final logistic models confirmed an effect of air pollution on lung cancer risk, although the estimates for women showed no clear trend with air pollution levels. With the same air pollution classification as in males, an increased relative risk for the medium level and a decrease for the high level was found in women. This may be due to a selection bias of female controls. The lower risk for air pollution seen in younger men ( $<60$ years) than in older men suggest that the older persons run a higher risk of lung cancer related to common air pollutants as a result of possible longer duration of residency at the last address (20-30 years, with increasing tendency for stability in higher polluted areas) but the relatively stronger effect of air pollution in older persons in comparison to occupational variables may also in part result from a recall bias for very old subjects.

Lung cancer risk due to air pollution may be underestimated in comparison to that of smoking, as the effect of air pollution was not compared with a "null category", ie, a region without any air pollution, while never smokers served as natural reference group for smoking. The results may also be influenced by the fact that smoking habits were measured at the individual level while air pollution was estimated in broad areas of residency and did not necessarily reflect the total burden of exposure to polluted air. A classification bias resulting in underestimation of the true effects could have arisen when persons under study lived in less polluted areas but worked in more polluted areas, although occupational dust exposure was controlled. The validity of air pollution estimates is limited by the fact that the total air pollution residential history could not be taken into consideration since the questionnaire addressed only the last place of residence. However, the population in the Cracow urban area is relatively stable, the data showing a mean duration of residence at the last address of about 30 years.

In a recent ecological study, ${ }^{25}$ the effect of air pollution was assessed in Harris County, Texas, USA. Total suspended particulate matter was used for a classification into different air pollution levels. A slight association between lung cancer mortality and air pollution was found, although the suspended particle values were considerably lower than in parts of the Cracow area.

The risk estimates associated with cigarette smoking were significantly increased among males and females and were found to rise with increasing levels of cumulative smoking and with decreasing age at start smoking in both males and females. After additional adjustment for potential confounders, cigarette consumption remained the strongest predictor of lung cancer risk. Our case-control study data concerning lung cancer risk patterns due to tobacco consumption are quantitatively in line with the largest multicentre study of its kind carried out in Europe by Lubin et al. $^{35}$

Besides smoking, two occupational variables were considered in our analysis, ie, a long term exposure ( $>20$ years) to suspected occupational hazards and the job category (manual $v$ nonmanual workers). Although the latter variable used for females provides no direct information 
Table IX Odds ratio estimates (adjusted to age) for non-smokers based on multiple logistic model

\begin{tabular}{llllcll}
\hline Sex & Variable & & Cases & Controls & RR & $95 \%$ CI \\
\hline Male & $\begin{array}{l}\text { Occupational } \\
\text { exposure }\end{array}$ & no & 32 & 182 & 1.0 & \\
& yes & 17 & 39 & 2.37 & $1.18-4.77$ \\
& Air pollution & low & 32 & 154 & 1.0 & \\
& & high & 17 & 67 & 1.45 & $0.74-2.87$ \\
Female & Manual worker & no & 67 & 152 & 1.0 & \\
& & yes & 12 & 14 & 1.57 & $0.84-2.92$ \\
& Air pollution & low & 56 & 117 & 1.0 & \\
& & high & 23 & 49 & 1.16 & $0.48-2.80$ \\
\hline
\end{tabular}

$\mathbf{R R}=$ relative risk; $\mathrm{CI}=$ confidence interval

on specific occupational hazards, it is considered an appropriate measure to control further for confounding. Both occupational variables modified the risk of cancer significantly; however, their effects were not so strongly associated with lung cancer as smoking. Occupational risk estimates also remained significant after standardisation by age and smoking habits. The estimates of lung cancer risk due to occupation in men were found to be in good agreement with other similar studies. Simonato $e t a^{36}$ give an overview of other case-control studies on lung cancer and occupational exposure, showing that the majority of relative risk estimates of exposure to known lung carcinogens lie around 2 . Socioeconomic status, known to be a major determinant of lung cancer, did not show an additional effect in this study.

Information on smoking and occupation was collected from next of kin in our study, and mostly obtained from surviving spouses or offsprings. There may be some doubts on the reliability of the next of kin interviews, especially regarding more complex items such as the employment history. The questionnaire was therefore limited to very simple questions relating to easily available information. The close agreement between the derived estimates and those from other studies ${ }^{36}$ is, however, encouraging and is against the existence of severe bias. Many other observations support the view that surrogate interviews are reliable. It appeared that correct identification of smoking status by next of kin is generally good and the level of agreement for various surrogates combined was remarkably similar to living subjects. ${ }^{37-39}$ In our study the comparability in the quality of information coming from different surrogates was indirectly confirmed since the estimates of risks did not change when controlled for the source of data (spouse $v$ others).

A possible confounding effect of smoking on the effect of air pollution was adjusted for by using a multivariate analysis where, as mentioned above, no modification of effect was noted. In addition, table $\mathrm{X}$ shows that there was little

Table $\boldsymbol{X}$ Percentage of cases and controls in highest smoking categories ( $>20$ cigarettes daily) by air pollution levels

\begin{tabular}{lll}
\hline Air pollution & Cases & Controls \\
\hline \multicolumn{1}{c}{ Males } & & \\
Low & $32 \cdot 3$ & $16 \cdot 2$ \\
Medium & $28 \cdot 0$ & $20 \cdot 0$ \\
High & $30 \cdot 5$ & $18 \cdot 4$ \\
& \multicolumn{2}{c}{ Females } \\
Low & $12 \cdot 3$ & $0 \cdot 75$ \\
Medium + high & $17 \cdot 8$ & $4 \cdot 8$ \\
\hline
\end{tabular}

correlation between smoking and air pollution. We have chosen to illustrate this by presenting in table X the proportion of heavy smokers ( $>29$ cigarettes daily) by sex, case/control status and air pollution level. It can be seen that for male cases and controls there was an almost constant proportion of heavy smokers at each air pollution level (for cases around 30\%, for controls around $18 \%$ ). The percentages for females, which are based on smaller numbers, are not as consistent as those for males.

There are other risk factors, not included in this study, which are supposed to play a role in the aetiology of lung cancer, such as passive smoking, ${ }^{40}$ radon, ${ }^{41}$ and nutritional factors. ${ }^{42} \mathrm{We}$ think that the degree to which not controlling for these variables may have affected our results is negligible. In our analysis a confounding effect of smoking on the other factors was not found, and thus a confounding effect of passive smoking is also unlikely. To our knowledge, radon is of no relevance in the Cracow area. A confounding effect of nutrition is improbably since we found no relation between lung cancer and social class.

In summary, this study shows that under the conditions found in Cracow, air pollution may increase lung cancer risk. It acts multiplicatively with known risk factors such as smoking and occupational exposure.

The field study was supported by a grant from the Cancer Research Programme coordinated by the Institute of Lung Disease in Warsaw, Poland. The analysis of the data was financially supported by the German Cancer Research Centre, Heidelberg, FRG.

The authors gratefully acknowledge Heike Weis' secretarial help and Renate Angerer's technical assistance.

1 IARC Monographs. Evaluation of the carcinogenic risk of chemicals to humans. Vol. 38, Tobacco smoking. Lyon: IARC, 1986

2 Enstrom JE. Rising lung cancer mortality among nonsmokers. I Natl Cancer Inst 1979; 62: 755-60.

3 Falk HL, Kotui P. An assessment of factors concerned with carcinogenic properties of air pollutants. NCI Monograph carcinogenic properties of air pollutants. NCI Monograph No. 9. Bethesda, Maryland:
Education and Welfare, 1962.

4 Fulcino H, Mimura S, Inone K, Yamane Y. Mutagenicity of Fulcino H, Mimura S, Inone K, Yamane Y. Mutagenic
airborne particles. Mutation Res 1982; 102: 237-47.

5 Walker RD, Connor TH, McDonald EJ, et al. Correlation of mutagenic assessment of Houston air particulate extracts in relation to lung cancer mortality rates. Environ Res 1982; 28: 303-12

6 Alink GM, Smit HA, van Houdt JJ, Kolkman JR, Bolei JSM. Mutagenic activity of airborne particulates at nonindustrial locations. Mutations Res 1983; 116: 21-34.

7 Haenszel W, Taenber KE. Lung cancer mortality as related to residence and smoking and smoking histories. II. White females. I Natl Cancer Inst 1964; 32: 803-38.

8 Hagstrom RM, Spragne HA. The Nasteville air pollution study. VIII. Mortality from cancer in relation to air study. VIII. Mortaity from cancer in relation
pollution. Arch Environ Health 1967; 15: 237-47.

pollution. Arch Environ Health 1967; 15: 237-47.
9 Hammond E, Garfinkel L. General air pollution and cancer in the United States. Prev Med 1980; 9: 206-11.

10 Miller AB. Epidemiology and etiology of lung cancer. Miller AB. Epidemiology and etiology of
Exerpta Med Int Congr Ser 1980; 525:9-26.

Exerpta Med Int Congr Ser 1980; 525: 9-26.
11 Higgins ITT. Air pollution and lung cancer: diesel exhaust, Higgins ITT. Air pollution and lung cancer: diese
coal combustion. Prev Med 1984; 13: 207-18.

12 Doll R, Peto R. The causes of cancer: quantitative estimates of risks of cancer in the United States today. $\mathcal{I N a t l}$ Cancer Inst 1981; 60: 1191-265.

13 Carnow BW, Meier P. Air pollution and pulmonary cancer Arch Environ Health 1973; 27: 207-18.

14 Higginson J, Jensen OM. Epidemiological review of lung cancer in man. In: Air pollution and cancer in man. Lyon: IARC Scientific Publications No. 16, 1977.

15 Jedrychowski W, Szal H, Cholewka-Cabaj K. Monitoring of lung cancer death among inhabitants in Cracow (in Polish). Przeg Lek 1984; 41: 309-14.

16 Levin ML, Haenszel W, Carrol BE, Gerhardt PR, Handy $\mathrm{VH}$, Ingraham SC. Cancer incidence in urban and rural areas of New York State. I Natl Cancer Inst 1960; 24: 1243-57.

17 Haenszel $W$, Loveland DB, Sirken MG. Lung cancer mortality as related to residence and smoking histories: $I$. White males. $\mathcal{Y}$ Natl Cancer Inst 1962; 28: 947-1001. 
18 Weiss W. Lung cancer mortality and urban air pollution. $A m$ I Public Health Bull 1968; 17: 773-5.

19 Doll R. Mortality from lung cancer among non-smokers. $\mathrm{Br}$ f Cancer 1953; 7: 303-21.

20 Stocks P. Cancer in North Wales and Liverpool Region (British Empire Cancer Campaign, supplement to part II) Eastbourne, Sussex: Summerfield and Day, 1957.

21 Hammond EC, Horn D. Smoking and death rates: Report on forty-four months of follow-up of 187,783 men. $¥ A M A$ 1958; 166: 1294-308.

22 Dean G. Lung cancer and bronchitis in Northern Ireland, 1960-2. Br Med F 1966; 1: 1506-14.

23 Buell $\mathrm{Ph}$, Dunn JE, Breslow L. Cancer of the lung and Los-Angeles-type air pollution. Cancer 1967; 20: $2139-47$.

24 Hitosugi M. Epidemiological study of lung cancer with special reference to the effect of air pollution and smoking habits. Inst Public Health Bull 1968; 17: 237-56.

25 Buffler A, Cooper P, Stinnett S, et al. Air pollution and lung cancer mortality in Harris County, Texas, 1979-1981. Am $\mathscr{f}$ Epidemiol 1988; 128: 683-99.

26 Vena JE. Air pollution as a risk factor in lung cancer. $\mathrm{Am} \mathrm{f}$ Epidemiol 1982; 116: 42-56.

27 Becher H, Jedrychowski W, Flak E, Gomola K, Wahrendorf J. Lung cancer, smoking and employment in foundries. Scand $\mathcal{f}$ Work Environ Health 1989; 15: 38-42.

28 Suess MJ, Grefen K, Reinisch DW, eds. Ambient air pollutants from industrial sources. A reference handbook. pollutants from industrial sources.

29 Szal H, Krzyzewski Zd. Spatial distribution and trends in the air pollution in Cracow over 1973-1980 period (in Polish). Ochr Pow 1985; 19: 9-12.

30 Breslow NE, Day NE. Statistical methods in cancer research, Scientific Publications No 32, 1980.
31 Bruzzi P, Green SB, Byar DP, Brinton LA, Schairer C. Estimating the attributable risk for multiple risk factors Estimating the attributable risk for multiple risk factors 32 Breslow NE, Storer BE. General relative risk functions for Breslow NE, Storer BE. General relative risk functions for

33 Wahrendorf J. Discussion of DR Cox's paper on "Interaction". Int Statist Rev 1984; 52: 39-30.

34 Damber LA, Larsson LG. Occupation and male lung cancer: a case-control study in northern Sweden. $\mathrm{Br} \mathcal{F}$ Ind Med 1987; 44: 446-53.

35 Lubin JH, Blot WJ, Berrino F, et al. Patterns of lung cancer risk according to type of cigarette smoked. Int $\mathcal{F}$ Cancer 1984; 33: 569-76.

36 Simonato L, Fletcher A, Vinies B. Estimates of the proportion of lung cancers due to occupation. Carcinogenesis 1988; 9: 1159-65.

37 McLaughlin JK, Dietz MS, Mehl ES, Blot WJ. Reliability of surrogate information in cigarette smoking by type of informant. Am ₹ Epidemiol 1987; 126: 144-6.

38 Lerchen ML, Samet JM. An assessment of the validity of questionnaire responses provided by a surviving spouse. questionnaire responses provided

39 Shalat SL, Christiani DC, Baker EL. Accuracy of work history obtained from a spouse. Scand $\mathcal{f}$ Work Environ history obtained from a
Health 1987; 13: 677-69.

40 O'Neill IK, Brunnemann KD, Dodet B, Hoffmann D, eds Environmental carcinogens-methods of analysis and exposure measurement. Vol. 9-Passive smoking. Lyon IARC Scientific Publications No 81, 1987.

41 National Research Council, Committee on the Biological Effects on Ionizing Radiation (BEIR). Health risks of radon and other internally deposited alpha-omitters. Washington DC: National Academy Press, 1988.

42 Byers TE, Graham S, Haughey BP, Marshall JR, Swanson MK. Diet and lung cancer risk: findings from the wester New York diet study. Am $\mathcal{f}$ Epidemiol 1987; 125: 351-63. 